\title{
An equivalent fluid/equivalent medium approach for the numerical simulation of coastal landslides propagation: theory and case studies
}

\author{
P. Mazzanti and F. Bozzano \\ Dipartimento di Scienze della Terra, Università di Roma "Sapienza", P.le Aldo Moro 5, 00185 Rome, Italy \\ Received: 23 July 2009 - Accepted: 4 November 2009 - Published: 25 November 2009
}

\begin{abstract}
Coastal and subaqueous landslides can be very dangerous phenomena since they are characterised by the additional risk of induced tsunamis, unlike their completelysubaerial counterparts. Numerical modelling of landslides propagation is a key step in forecasting the consequences of landslides. In this paper, a novel approach named Equivalent Fluid/Equivalent Medium (EFEM) has been developed. It adapts common numerical models and software that were originally designed for subaerial landslides in order to simulate the propagation of combined subaerial-subaqueous and completely-subaqueous landslides. Drag and buoyancy forces, the loss of energy at the landslide-water impact and peculiar mechanisms like hydroplaning can be suitably simulated by this approach; furthermore, the change in properties of the landslide's mass, which is encountered at the transition from the subaerial to the submerged environment, can be taken into account. The approach has been tested by modelling two documented coastal landslides (a debris flow and a rock slide at Lake Albano) using the DAN-W code. The results, which were achieved from the back-analyses, demonstrate the efficacy of the approach to simulate the propagation of different types of coastal landslides.
\end{abstract}

\section{Introduction}

Coastal landslides are complex phenomena that couple not only the features of both subaerial and submerged landslides but also a transition phase between the two different environments during the propagation along a slope. This is a matter

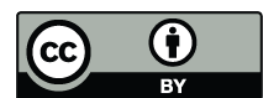

Correspondence to: P. Mazzanti (paolo.mazzanti@uniroma1.it) that is still not deeply investigated and understood in the scientific community.

Among the different types of coastal landslides, large, fast and extremely fast landslides, which are characterised by the additional hazard of induced tsunami waves, are of particular interest. The tsunamigenic potential of both completelysubmerged landslides and subaerial landslides that impact water has been widely investigated (Jorstad, 1968; Plafker and Eyzaguirre, 1979; Assier-Rzadkiewicz et al., 2000; Papadopoulos and Kortekaas, 2003; Wagner et al., 2003; Hubbard et al., 2005; Panizzo et al., 2005).

The study of coastal landslides requires a combined subaerial-submerged investigation (Mazzanti, 2008a). In addition, if the consequences of such landslides must be analysed, tools that are able to simulate the propagation of landslides in terms of mass distribution, runout distance and velocity are also needed.

\section{Numerical modelling of coastal landslides}

Recently, in the field of subaerial landslides, great attention has been focused on predicting the volume, velocity, runout and mass distribution. Two different approaches are common:

- An empirical approach that is mainly based on historical data records. Among these, the most common method which predicts the runout distances, deals with an apparent inverse relationship between the volume and the Fahrböschung (Heim, 1932) of landslides that have already occurred: several linear regression equations have been proposed (Scheidegger, 1973; Corominas, 1996) that are able to predict the landslide's runout and velocity if the landslide's volume is given. De Blasio et

Published by Copernicus Publications on behalf of the European Geosciences Union. 
al. (2006b) obtained a similar plot by comparing different types of subaerial and submerged landslides. Such an approach, even if very powerful and extensively used for prediction purposes, has several limitations that are mainly related to the large variability of landslide features, such as topography, rheology and so on.

- An analytical approach, which is based on the mechanics of the movement, involves the solution of a system of governing equations for the motion, either in a closedform or numerically (see at Hungr et al., 2005a for an extensive review).

Due to the high complexity of the mechanisms that are involved in the post-failure stage of fast subaerial landslides (Cruden and Varnes, 1996), few models have been built that try to capture the "real" physics of the movement (Denlinger and Iverson, 2001, 2004; Campbell et al., 1995). The most appropriate models that are used adopt a semiempirical approach (McDougall, 2006) that is based on the principle of the equivalent fluid, which was formalised by Hungr (1995). This approach, which is extensively described in Hungr (1995), assumes that the moving mass behaves like a fluid whose rheological features cannot be measured through laboratory or in situ instruments but can only be obtained by the back-analysis of some real past events. The approach is defined as "semi-empirical" because it uses a numerical model that accounts for the main physical features of the phenomenon. However, at the same time, it needs a large historical record of real events in order to calibrate the parameters.

In the past few years, these models are becoming fully 3D (McDougall et al., 2008; Mazzanti et al., 2009), i.e. they are able to simulate the distribution of the mass over real topography, and reliable enough to be used to assess the consequences that are related to the occurrence of catastrophic, fast subaerial landslides (Iovine et al., 2003; Malet et al., 2004; Hürlimann et al., 2006; Wang et al., 2006; Toyos et al., 2008). Their effectiveness is the result of several backanalyses of past phenomena that allow parameters to be constrained.

However, even if these models are calibrated upon real events and can thus be considered to be more "practical" than "theoretical," they are often based, or at least validated, on laboratory experiments (Bagnold, 1954, 1956; Hungr and Morgenstern, 1984; Savage and Hutter, 1989; Denlinger and Iverson, 2001; Iverson and LaHusen, 1993; Major and Pierson, 1992; O’Brien and Julien, 1988; Pearsons et al., 2001).

With regard to landslides that occur underwater, less experimental results are available (Marr et al., 2001; Talling et al., 2002; Ilstad et al., 2004; Felix and Peakall, 2006; Breien et al., 2007) and the direct observation of real phenomena is at the present time impossible. Furthermore, analysis of landslide deposits is more difficult in the submerged environment; thus, indirect information is also limited. As a consequence, few rheological and phenomenological constraints are available and, thus, few numerical models have been developed for propagation in submerged environments. Imran et al. (2001) built the bi-dimensional BING model that is suitable to analyse muddy and viscous flow-like mudflows or cohesive debris flows, whose resistance law can be derived by the Herschel-Bulkley (Laigle and Coussot, 1997), Bingham (Sousa and Voight, 1991; O'Brien et al., 1993; Whipple, 1997) or bilinear rheological relations (Locat, 1997). Some models that analyse turbidity currents are available, and recently, a cellular automata model was also developed that is suitable for such a phenomenon (Salles et al., 2007). Only one numerical model that can simulate underwater granular flows (like rock and debris avalanches) with a Savage-Hutter type model (Fernández-Nieto et al., 2008) has been recently developed; nevertheless, this model has not been applied to real landslides yet.

A further degree of complexity is related to the simulation of combined subaerial-submerged events since they are characterised by a very complicated air-water transition.

In spite of the difficulties of the investigation and modelling of both submerged and coastal landslides, an increasing number of case studies will be available in the future that will allow to constrain and calibrate the numerical models.

\section{The equivalent fluid/equivalent medium approach}

The proposed approach is named equivalent fluid/equivalent medium. It represents a simplified solution for numerical modelling of coastal landslides. Formally speaking, the equivalent fluid approach that has been used since the ' $80 \mathrm{~s}$ to simulate subaerial landslides should also be called equivalent fluid/equivalent medium. It is based in fact on the assumption that the landslide moves like an equivalent homogeneous fluid (usually depth integrated) in an equivalent medium (air). Nevertheless, in the case of subaerial landslides, both the drag and buoyancy forces can be reasonably neglected even if the drag forces that are exerted by the air can be sometimes relevant (e.g. Issler, 2003).

But, in water, the interaction between the mass and the medium cannot be neglected because it controls some processes that modify the motion of the mass. These complex processes are well constrained for the movement of very simple shape objects but they are not fully understood for the motion of deformable large masses.

A model that is suitable for the simulation of coastal landslides has to account for the mass-water interaction and, at the same time, it must be solid, have few parameters and be simple to use (in order to be calibrated for a number of case studies as large as possible).

It is suggested that an approach, which allows for the use of common and well-known models developed for subaerial landslides could represent, once calibrated to real events, a 
simple and useful tool for the investigation of subaqueous landslides.

The following aspects must be taken into account in the numerical simulation of coastal landslides: 1) the buoyancy effect; 2) drag forces; 3 ) the added mass factor (only for very thick landslides); 4) peculiar mechanisms like hydroplaning (Mohrig et al., 1998), and 5) the sudden change of environment (water impact) since it can produce an impulsive loss of energy and several modifications in the flow behaviour.

This approach needs some solutions in order to consider some of the main aspects that are listed above. In the next paragraphs, these solutions will be discussed together with a brief physical description of the mechanisms.

\subsection{Buoyancy effect}

The buoyancy is the force that obeys Archimedes's principle, which states that a body that is immersed in a fluid is buoyed up by a force that is equivalent to the mass of the displaced fluid. This force is directed upwards and can be seen as a change in the gravitational acceleration that results in the $g^{\prime}$ value that is reported in Eq. (1):

$g^{\prime}=g\left[\left(\rho-\rho_{w}\right) / \rho\right]$

Given

$\left(\rho-\rho_{w}\right)=\rho^{\prime}$

Equation (1) can be written as

$g^{\prime}=g \cdot\left(\rho^{\prime} / \rho\right)$

where $g$ is the gravitational acceleration; $\rho$ is the average density of the material that is involved in the landslide and $\rho_{w}$ is the density of water $\left(\cong 1 \mathrm{Mg} / \mathrm{m}^{3}\right)$.

In some codes, where the unit weight is used instead of the density, this aspect is still more clear.

In practice, in order to obtain the reduction in gravity, the value of :

$\rho^{\prime}=\left(\rho-\rho_{w}\right)$

is used in the submerged environment in spite of $\rho$. Some limitations are related to the use of this expedient in the proposed approach, which will be discussed below.

A landslide that moves partly in the subaerial and partly in the submerged environment can be modelled by changing the value of the density (or related values) as the water level is approached.

In the case of a code that does not permit this change along the path, an average value for the subaerial and submerged parts must be used; obviously, in terms of the velocity distribution, the numerical simulation cannot be considered very effective when it uses this approximation.

\subsection{Drag forces}

When a body moves through a fluid, an interaction between the body and the fluid occurs. This interaction can be described in terms of a shear stress, which is due to viscous effects, and a normal stress, which is due to pressure. Thus, a drag force exists, which is directed parallel to the flow direction, and resists the movement of the body through the fluid. It is made up of friction forces that act parallel to the body's surface plus a pressure force that acts in the direction that is perpendicular to the object's surface. These forces are described by the following equation:

$D=\frac{1}{2} \rho_{w} \cdot U^{2} \cdot A \cdot C_{d}$

where $\rho_{w}$ is the density of water, $U$ is the velocity of the mass, $A$ is the so-called "reference area" of the moving mass that corresponds to the area of the projection of the object onto a plane that is perpendicular to the direction of motion (however, it is largely dependent on the shape of the object and can be seen as the area that interacts with the surrounding medium) and $C_{d}$ is a dimensionless parameter that mainly depends on the shape of the body and on the Reynolds number (Batchelor, 1973). The value of $C_{d}$, which strongly affects the drag force, was derived from laboratory experiments on regularly-shaped objects, even though it is practically impossible to calculate its value for very complex objects that continuously modify their shape during the flow, such as a landslide.

The drag has to be computed as an additional resisting force that is proportional to the square of the velocity.

In several codes, which include the Voëllmy rheology (Voëllmy, 1955), the resisting forces can be written as (Hungr, 1995):

$T=A_{b} \cdot \gamma \cdot H\left(\cos \alpha+\frac{a_{c}}{g}\right)+A_{b} \cdot \gamma \cdot \frac{v^{2}}{\xi}$

where $A_{b}$ is the basal area of the body, $\gamma$ is the unit weight $(\rho g), H$ is the height of the moving body, $a_{c}$ is the centrifugal acceleration (dependent on the vertical curvature of the path), $\alpha$ is the slope angle, $g$ is the gravitational acceleration, $v$ is the velocity of the body and $\xi$ is the turbulence coefficient of friction. The second term of Eq. (6), in the original purpose of Voëllmy (1955), accounted for a basal frictional term that is proportional to the square of the velocity. In the approach that is proposed here, the drag force is then simulated by modifying the turbulence coefficient of friction, which is proportional to the square of the landslide's velocity, by an amount that is inferred from the back-analysis. This coefficient will account in a fictitious way for either the inner turbulence effects in the landslide's mass (assumed as an equivalent fluid) or for the drag forces that are due to the interaction of the moving mass with the surrounding water.

The main intrinsic limitation in such a solution is related to the density (or unit weight), which is used in Eq. (6), where 
it refers to $\rho^{\prime}$ (see at Eq. 4) instead of $\rho_{w}$. Nevertheless, such a limitation can be overcome by modifying the turbulence coefficient since there is a direct relation between the terms $\gamma(\rho)$ and $\xi$.

\subsection{Added mass}

When a body accelerates in a fluid, it must also accelerate part of the fluid. This force can be defined as the inertia that is added to a system because an accelerating or decelerating body must displace some volume of the surrounding fluid as it moves through it.

The added mass can be incorporated into most physics equations by considering a "virtual mass" that is given by the sum of the body's mass and the added mass. For example, a simple formulation of the added mass for a spherical body permits Newton's second law of dynamics to be written in the form:

$F=\left(m+m_{\text {added }}\right) \cdot a$

where $m$ is the mass of the body, $m_{\text {added }}$ is the virtual mass and $\mathrm{a}$ is the acceleration of the body.

This effect is important for objects when the section that is perpendicular to the flow direction is large in comparison to the length along the flow direction and when the density of the body and the medium are similar. On the contrary, the added mass is less effective for bodies that mainly extend along the flow direction.

Since landslides mainly extend along the flow direction and since their densities are usually quite higher that those of the fluid, the added mass force can be neglected without significant errors (Lastras et al., 2005). Nevertheless, this effect must be taken into account in the uncommon cases of very thick landslides that are characterised by a low density (not presented in this paper).

\subsection{Impact with the water's surface}

The impact of landslides against water has been poorly investigated (Mazzanti, 2008b) even if the water-impact is well-known for other objects, see for example by von Karman (1929), Wagner (1932), Fasanella et al. (2003) and Kleefsman et al. (2005). The moving mass experiences a large impact load as it strikes the water's surface in front of it and becomes fully submerged while descending towards the sea or lake bottom. During the impact, the mass significantly reduces its velocity thus modifying its momentum (Mazzanti, 2008b). However, due to the limited research on this topic at present it is quite impossible to quantitatively estimate this value. This impulsive loss of energy and consequent deceleration can be tentatively simulated by setting a high frictional layer, a few meters long, near the coastline (Fig. 1). This solution is able to reproduce the effect of a sudden and localised brake in the movement of the mass that results in a quasi-instantaneous loss of velocity. Nevertheless, this effect is very difficult to quantify. Hence, such a solution can only be used for qualitative consideration of the phenomena that occur at impact.

\subsection{Additional mechanisms that occur underwater}

Some particular mechanisms, which play a major role in subaqueous mass movements, can be taken into account by using the EFEM approach, such as hydroplaning (Mohrig et al., 1998; Harbitz et al., 2003; De Blasio et al., 2004) and glide blocks (De Blasio et al., 2006a; Engvik et al., 2006).

These mechanisms, which are considered to be effective only for high-speed mass movements, imply a drastic reduction in the basal friction of the landslide that is due to the presence of a water layer, which is trapped between the landslide and the slope. Such an effect only occurs when the landslide body reaches a threshold velocity (Mohrig et al., 1998; De Blasio et al., 2004).

Since hydroplaning implies a reduction in basal friction, it can be reproduced by setting a very low value of the basal friction parameters $(\mu)$ in the Voëllmy rheology once the threshold velocity (which must be previously computed) is reached in the simulation.

In other words, the simulation can be divided into two steps (Fig. 2).

1. First, a simulation is carried out by setting the parameters that do not take into account the hydroplaning effect; hence, the travel distance, at which the threshold velocity is reached for hydroplaning, is obtained.

2. In the second step, a layer with a very low friction coefficient (close to zero) is applied from the distance that was obtained in the previous step.

Nevertheless, some limitations are connected to the use of such method. First of all, the extension of the area affected by the reduced friction is difficult to be estimated and no ways are available in literature to solve this uncertainty. Anyway, the method suggested above can be considered effective (even if simplified) and in line with the present scientific knowledge of the hydroplaning mechanism.

\section{Back analysis of combined subaerial - submerged landslides by the EFEM approach}

This approach requires an intense calibration to real cases in order to be validated and to constrain the parameters. In the past few years, such a calibration has been carried out for subaerial landslides by back-analysing different types of events; a large dataset of past landslides is now available (Hungr and Evans, 1996; McDougall, 2006) and the choice of parameters is reasonably constrained.

A widespread model for the post-failure analysis of subaerial landslides is DAN (Hungr, 1995), which is a "userfriendly" code that includes several rheological laws that are 


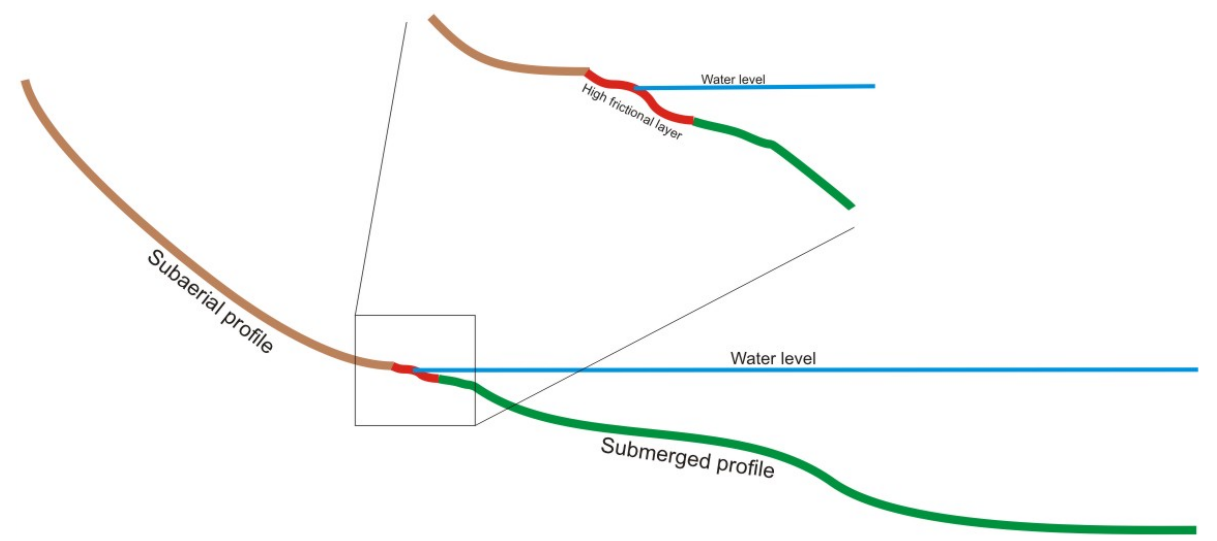

Fig. 1. Sketch that describes how to set the landslide to water impact in the EFEM approach.

able to capture the main features of a large variety of landslide types.

This model is available in two versions: the bidimensional version DAN-W (Hungr, 1995) and the threedimensional DAN3-D (McDougall and Hungr, 2004).

Both models are at the same time very flexible and suitable for application of the EFEM approach when the following features are considered:

- use of different rheological functions for different parts of the landslide's path;

- use of different density values for different parts of the landslide's path (only for DAN-W, not DAN3-D);

- use of Voëllmy rheology.

By applying the proposed approach, back-analyses of two coastal landslides were performed with DAN-W. These simulations represent a first validation of the approach and a first step in the calibration of the parameters.

\subsection{DAN-W}

The DAN-W model (Hungr, 1995) is based on a continuum finite difference numerical solution of the depth-averaged Lagrangian equations of motion. The solution includes an open rheological kernel in order to implement a variety of rheologies. For use in the solution, each rheological equation is integrated with respect to the depth under the approximate assumption that the horizontal shear stress within the flow varies linearly with depth. The model accounts for the third dimension by allowing for lateral widening and contraction of the landslide's body along the flow path while maintaining continuity and assuming shallow, broad channel flow. However, the distribution of the width along the path must be entered as an input parameter. The rheological relationships that are available in the program are extensively discussed in Hungr (1995); only the frictional rheology and the Voëllmy rheology, as modified by Hungr (1995), are discussed below.

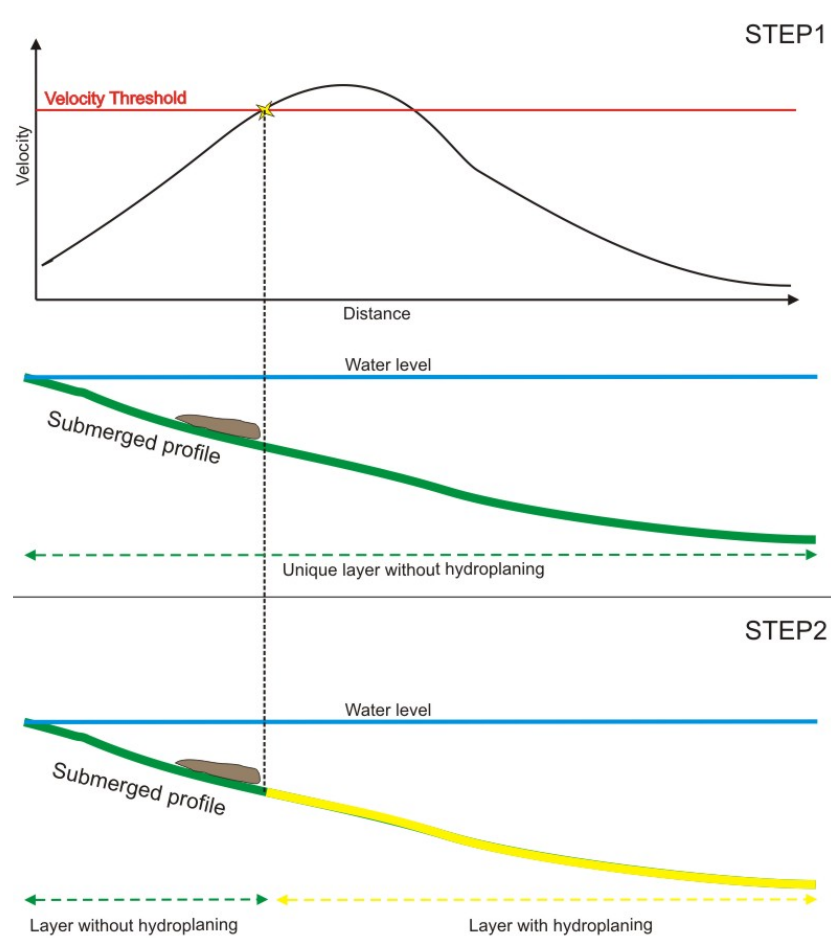

Fig. 2. Sketch that describes how to simulate the hydroplaning effect in the EFEM approach.

The rheological function for the frictional model is:

$\tau=\gamma \cdot H \cdot\left(\cos \alpha+\frac{a_{c}}{g}\right) \cdot\left(1-r_{u}\right) \tan \phi$

where $\tau$ is the resisting stress at the base of the flow, $\alpha$ is the slope angle, $\gamma$ is the unit weight of the flowing material, $H$ is the flow depth, $\phi$ is the dynamic friction angle, $r_{u}$ is the pore pressure coefficient, $a_{c}$ is the centrifugal acceleration (that is dependent on the vertical curvature of the path) and $g$ is the gravitational acceleration. 
The rheological function for Voëllmy rheology is:

$\tau=\gamma \cdot H \cdot\left(\cos \alpha+\frac{a_{c}}{g}\right) \cdot \mu+\gamma \frac{v^{2}}{\xi}$

where $\mu$ is the dynamic friction coefficient of the material (equal to $\tan \phi$ ) and $\xi$ is a turbulence coefficient with dimensions of $\left[L \cdot T^{-2}\right]$.

The main difference between the two functions is the additional resisting stress term that is proportional to the square of the velocity and that, in the original purpose of the model, accounts for the turbulence effects of the moving mass.

\subsection{The study area: Lake Albano (Rome, Italy)}

Lake Albano partially occupies a large multiple-maar depression that is located on the western slope of the Colli Albani volcanic edifice in central Italy, about $25 \mathrm{~km}$ southeast of the city of Rome.

The overall morphology of this multiple maar is featured by a low aspect ratio edifice that is characterised by gentlydipping outer slopes and steep inner slopes that correspond to the crater walls. The latter forms an elliptical crater rim, which has an axis maximum of about $4300 \mathrm{~m}$ and an axis minimum of about $2800 \mathrm{~m}$; Lake Albano has a maximum water thickness of about $165 \mathrm{~m}$. Regarding the geological setting in the inner slopes of the Albano maar, the hydromagmatic deposits (alternation of scoria lapilli beds and ash-rich layers that are generally cemented for zeolitisation and massive, chaotic, ash-matrix-supported, ignimbrite deposits that are up to 30-m thick) related to the Albano maar activities locally overlay thick banks of lava and scoria deposits that are ascribed to previous volcanic phases (Trigila, 1995). Due to its complex geological and geomorphological features, the inner slopes of the multiple-maar crater are characterised by several gravity-induced landforms (Mazzanti et al., 2007; Bozzano et al., 2009). Landslides can be recognised both in the subaerial and submerged parts of the slopes. They span a wide range of types (rock fall, debris flow, rock slide, complex landslides, debris slide and slump) and volumes (from $10^{0} \mathrm{~m}^{3}$ to $10^{6} \mathrm{~m}^{3}$ ).

Numerical modelling of the post failure propagation of two deeply-investigated past landslides (Fig. 3) is discussed below.

\subsection{Numerical modelling of the Lake Albano rock slide}

The Lake Albano rock slide (Mazzanti et al., 2007; Bozzano et al., 2008) has a large, completely-subaerial detachment area and a mainly-subaqueous deposit; based on geomorphological reconstruction, the total mobilised volume was about $3 \times 10^{6} \mathrm{~m}^{3}$ (Fig. 4).

The geological setting of the subaerial part of the hereby discussed slope sector is a superposition of hydromagmatic deposits upon a thick bank of lava lenses and scoria deposits. In particular, detailed geological surveys have pointed

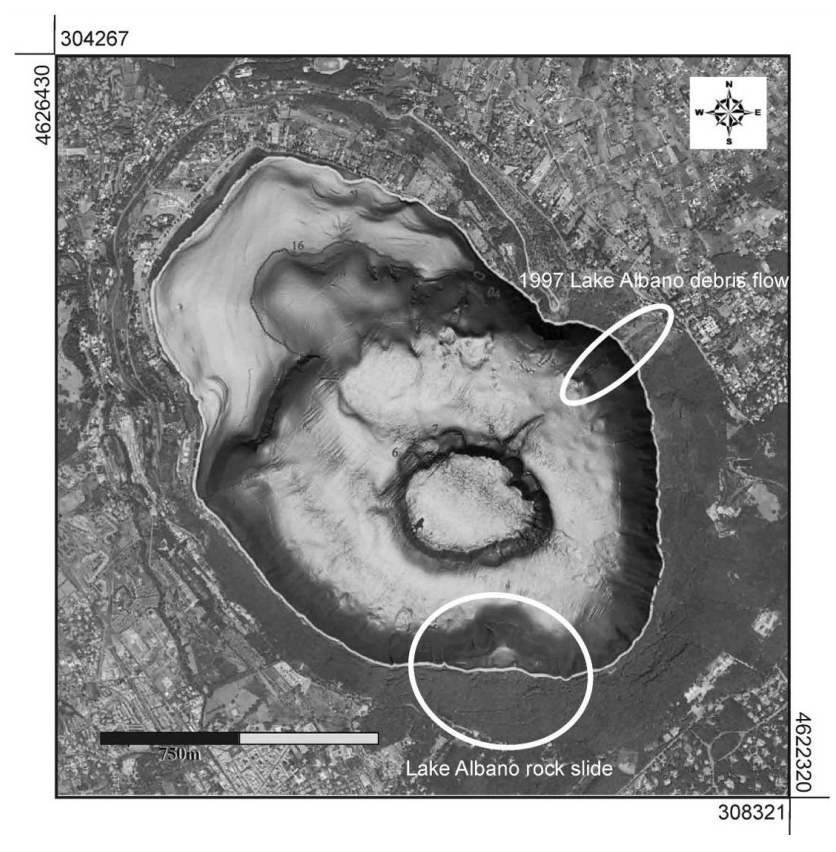

Fig. 3. Aerial photo and bathymetry shaded relief of Lake Albano. White ellipses enclose the Lake Albano rock slide and the 1997 debris flow (modified from Bozzano et al., 2009).

out that the material that is involved in the failure of the rock slope is constituted by massive and chaotic ignimbrite deposits; these deposits belong to one of the previouslymentioned intracrater facies of the hydromagmatic deposits, which are characterised by a marked dip slope attitude of the constitutive layers that is quite parallel to the slope. Based on morphologic evidence (such as the straight and sharp shape of both the crown and the flanks of the landslide scar, the flat morphology of the topmost part of the debris accumulation and the abrupt slope angle reduction in the lower part of the scar area) and on the geological-structural setting, this landslide can be preliminarily classified as a type-E (block slide with toe breakout) compound translational rock slide structurally controlled, according to Hungr and Evans (2004). It is also characterised by negligible inner deformations and fragmentation of the mass.

Such a mechanism is suitable for the first calibration of the EFEM approach. Several numerical simulations have been performed by DAN-W using the topography (Fig. 5) that was derived from the combination of aerial LiDAR and sonar multibeam swath bathymetric surveys (Pietrantonio et al., 2008). The rigid-block option (O. Hungr, personal communication, 2008) was applied while a frictional rheology for the subaerial path and a frictional or Voëllmy rheology for the submerged path were set. Different combinations of friction angles have been tested in the range of $33^{\circ}-22^{\circ}$, which correspond, respectively, to the peak and residual static friction angles that were estimated for the material along the sliding surface (Bozzano et al., 2008). 


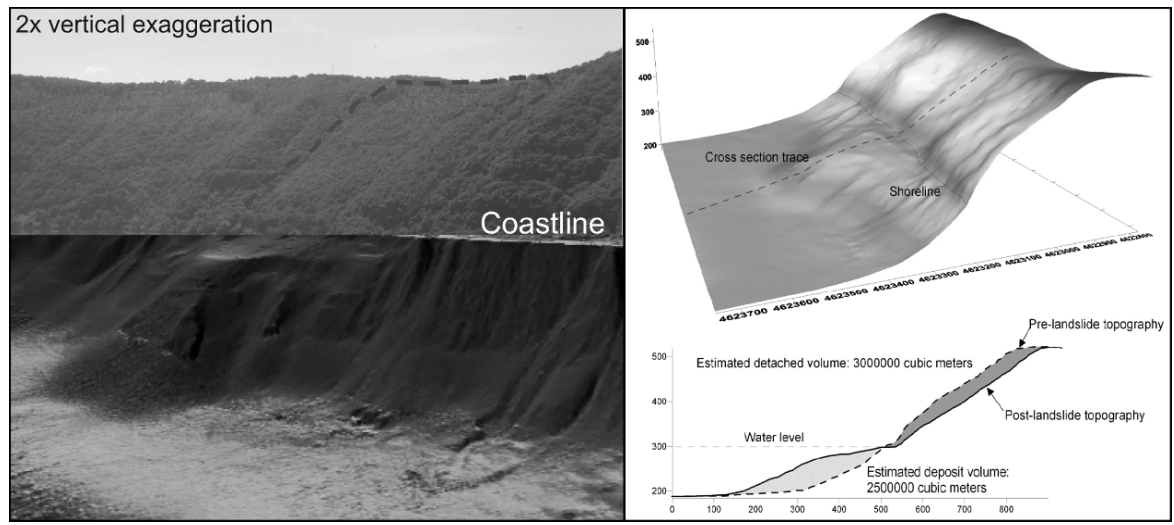

Fig. 4. 3-D perspective view and cross-section of the Lake Albano rock slide.

Table 1. Parameters used in simulations 1, 2 and 3 of the Lake Albano rock slide and achieved results.

\begin{tabular}{llll}
\hline & Case1 & Case2 & Case3 \\
\hline Subaerial Rheology & Frictional & Frictional & Frictional \\
Unit Weight $\left(\mathrm{kN} / \mathrm{m}^{3}\right)$ & 20 & 20 & 20 \\
Friction Angle $\left({ }^{\circ}\right)$ & 28 & 28 & 27 \\
Erosion $(\mathrm{m})$ & 0 & 0 & 0 \\
Subaqueous Rheology & Voëllmy & Frictional & Frictional \\
Unit Weight $\left(\mathrm{kN} / \mathrm{m}^{3}\right)$ & 10 & 20 & 20 \\
Friction Coefficient $(\mu)$ & $0.4\left(=\right.$ Tan $\left.22^{\circ}\right)$ & & \\
Turbulence Coefficient $(\xi)\left(\mathrm{m} / \mathrm{s}^{2}\right)$ & 40 & & \\
Friction Angle $\left({ }^{\circ}\right)$ & & 22 & 27 \\
Erosion $(\mathrm{m})$ & 0 & 0 & 0 \\
Peak Velocity $(\mathrm{m} / \mathrm{s})$ & 12 & 843 & 749 \\
Max Runout $(\mathrm{m})$ & 747 & & 749 \\
\hline
\end{tabular}

Both hydroplaning and the loss of energy during the impact with water have been neglected since we assume that these mechanisms are not relevant for a rock slide with a short runout and a small thickness to the length ratio.

In case 1 (Table 1), the EFEM approach has been applied by setting a unit weight of $\gamma=20 \mathrm{kN} / \mathrm{m}^{3}$ for the subaerial environment, which is consistent with the value for the material that was involved in the landslide (Bozzano et al., 2008), and a value of $\gamma^{\prime}=10 \mathrm{kN} / \mathrm{m}^{3}$ in the subaqueous path, which accounts for the buoyancy effect $\left(\gamma^{\prime}=\gamma-\gamma_{\text {water }}\right)$. The drag force in the subaqueous path has been simulated by using Voëllmy rheology with a friction coefficient value $\mu=0.4$ $\left(\phi=22^{\circ}\right.$ corresponds to $\left.\phi_{r}\right)$. A value of $\xi=40 \mathrm{~m} / \mathrm{s}^{2}$ has been obtained from the back-analysis of the real landslide runout of nearly $750 \mathrm{~m}$.

In order to infer the sensitivity of the proposed EFEM approach to the results, a simulation has been performed (case 2 of Table 1) with the same parameters as case 1 . However, the interaction with water has been neglected: both the drag force (frictional rheology with $\phi=22^{\circ}$ in the submerged path) and the buoyancy effect (setting $\gamma=\gamma=20 \mathrm{kN} / \mathrm{m}^{3}$ ) have been set to zero. Hence, this is not a back analysis that is calibrated to the runout.

Also, in case 3, the EFEM approach has not been applied and the real runout of the slide has been back-analysed by using a unique value of the friction angle and the unit weight for the entire path. This simulation has been performed in order to point out the differences in the velocity profile when the same final runout is reached in the cases where the EFEM approach is applied and neglected.

Table 1 summarises the parameters that were used in the three simulations and the obtained results while Fig. 6 shows the front velocity profiles that correspond to the three different cases. When comparing the first two cases, the runout of case 2 is about $100 \mathrm{~m}$ longer (where the presence of water is neglected) with respect to case 1 (Fig. 5) and has a higher peak velocity (Fig. 6). When comparing cases 1 and 3, where the same runout distance is imposed, a higher velocity has still been obtained when the presence of water is neglected. 


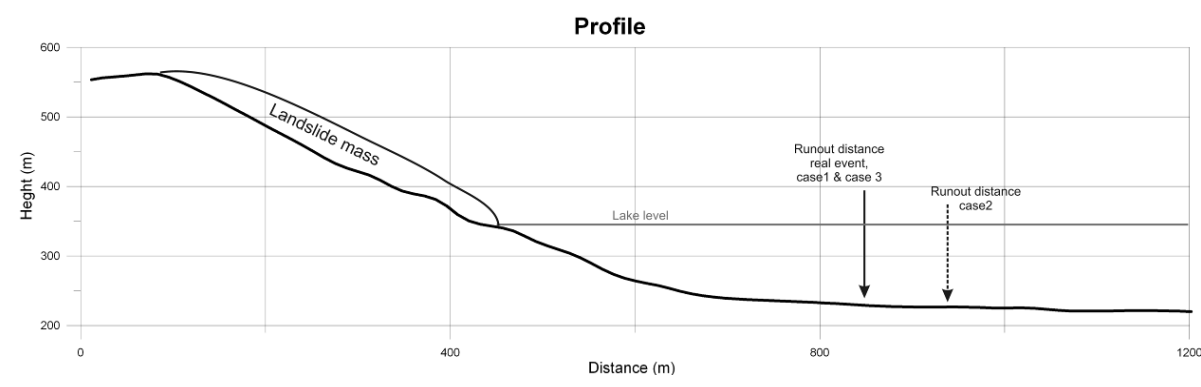

Fig. 5. Slope profile of the Lake Albano rock slide with the real and simulated runout distances obtained by using the parameters reported in Table 1 .
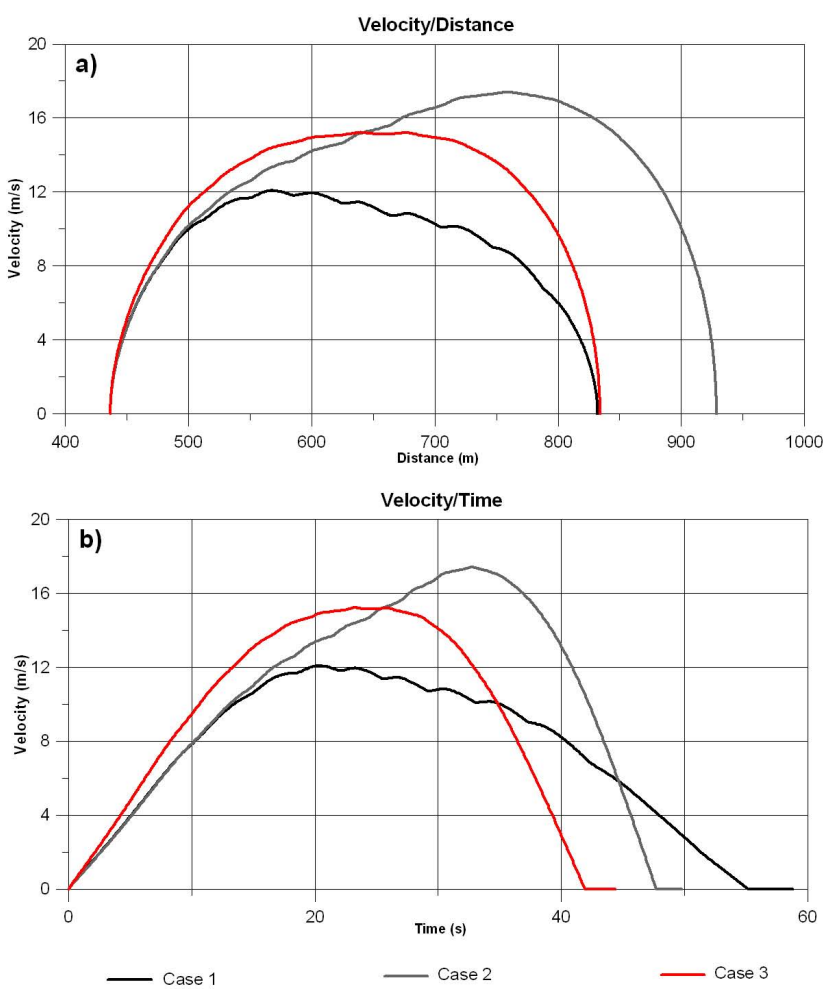

Fig. 6. (a) Front velocity versus distance and (b) Front velocity versus time of the Lake Albano rock slide computed in simulations 1, 2 and 3 of Table 1.

With regard to the velocity (Fig. 6), a lower value is obtained in case 1 with a peak of $12 \mathrm{~m} / \mathrm{s}$ as compared to the value of $17 \mathrm{~m} / \mathrm{s}$ and $15 \mathrm{~m} / \mathrm{s}$ that were obtained in cases 2 and 3 , respectively.

\subsection{Numerical modelling of the 1997 Lake Albano de- bris flow with DAN-W}

The debris flow (Mazzanti et al., 2007) occurred in the eastern slope of Lake Albano (Rome, Italy) on the 7 November 1997 after an intense rainfall event (Fig. 7). It began as a soil slide that mobilised about $300 \mathrm{~m}^{3}$ of eluvial material

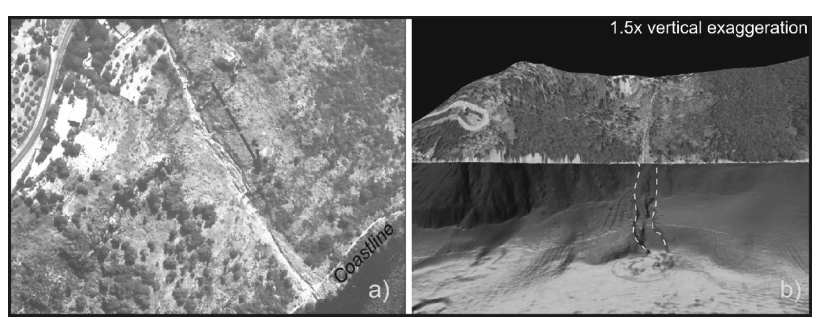

Fig. 7. (a) Aerial view of the debris flow that occurred in November of 1997. (b) Morphological reconstruction of the debris flow path and the accumulation in the submerged area.

before it was channelled within a steep impluvium (about $40^{\circ}$ ). It subsequently evolved as a debris flow that entrained a large amount of debris material along its path (Hungr et al., 2005b). A small amount of material was deposited at the coastline while the main part of the debris entered the water and continued both flow and erosion activity in the submerged part of the slope, thus generating a small tsunami wave less than $1 \mathrm{~m}$ high.

Detailed subaerial and submerged topographic data, which was derived from aerial LiDAR and sonar multibeam swath bathymetric surveys, was acquired in 2005 and 2006 (Pietrantonio et al., 2008). From this data, both the subaerial and submerged detachment and deposition areas can be mapped in detail and their volumes can be estimated (Mazzanti, 2008a, b).

Several numerical simulations have been performed with the DAN-W model by setting a Voëllmy rheology for both the subaerial and submerged paths.

In cases 1 and 2 (Table 2), the EFEM approach has been applied with and without considering the impact of water while the same values of the unit weight, friction coefficient and turbulence coefficient $\left(\gamma=18 \mathrm{kN} / \mathrm{m}^{3} ; \gamma^{\prime}=10 \mathrm{kN} / \mathrm{m}^{3}\right.$; $\mu=0.1 ; \xi_{a}=500 \mathrm{~m} / \mathrm{s}^{2} ; \xi_{w}=80 \mathrm{~m} / \mathrm{s}^{2}$ ) have been set for both the subaerial and submerged paths. The values that have been used in the subaerial part are reasonable when compared with similar events that are reported in the literature (Bertolo and Wieczorek, 2005; Revellino et al., 2004). For the submerged path, a lower value of the turbulence 


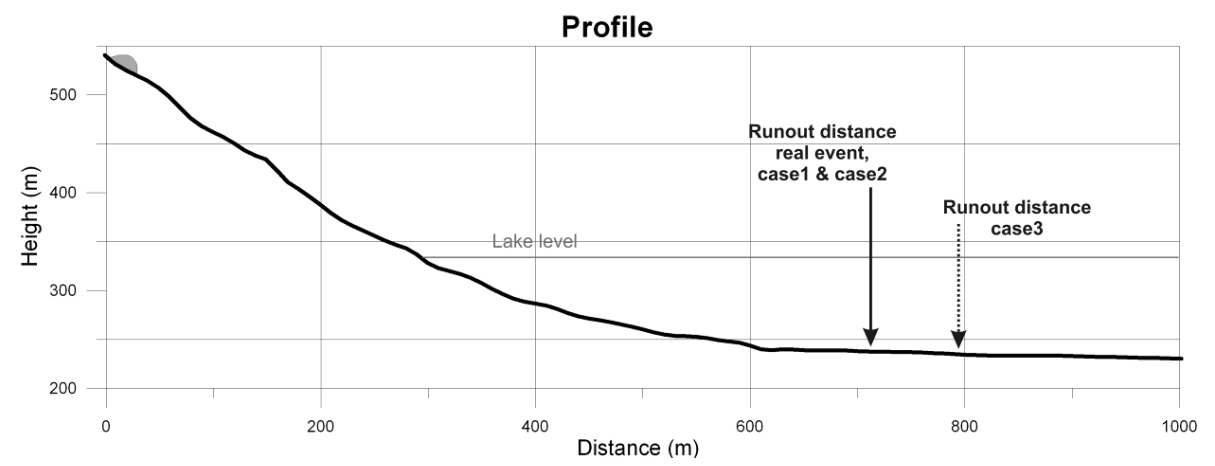

Fig. 8. Slope profile of the 1997 Lake Albano debris flow with the real and simulated runout distances that were obtained by using the parameters reported in Table 2.

Table 2. Parameters used in the simulations 1, 2 and 3 of the 1997 Lake Albano debris flow and achieved results.

\begin{tabular}{llll}
\hline & Case1 & Case2 & Case3 \\
\hline Subaerial Rheology & Voëllmy & Voëllmy & Voëllmy \\
Unit Weight $\left(\mathrm{kN} / \mathrm{m}^{3}\right)$ & 18 & 18 & 18 \\
Friction Coefficient $(\mu)$ & 0.1 & 0.1 & 0.1 \\
Turbulence Coefficient $(\xi)\left(\mathrm{m} / \mathrm{s}^{2}\right)$ & 500 & 500 & 500 \\
Erosion $(\mathrm{m})$ & 2 & 2 & 2 \\
Subaqueous Rheology & Voëllmy & Voëllmy & Voëllmy \\
Unit Weight $\left(\mathrm{kN} / \mathrm{m}^{3}\right)$ & 10 & 10 & 18 \\
Friction Coefficient $(\mu)$ & 0.1 & 0.1 & 0.1 \\
Turbulence Coefficient $(\xi)\left(\mathrm{m} / \mathrm{s}^{2}\right)$ & 80 & 80 & 500 \\
Friction Angle & & & \\
Erosion $(\mathrm{m})$ & 2 & 2 & 2 \\
Water Impact & Yes & no & no \\
Peak Velocity $(\mathrm{m} / \mathrm{s})$ & 23 & 23 & 23 \\
Max Runout $(\mathrm{m})$ & 728 & 730 & 794 \\
\hline
\end{tabular}

coefficient $\left(\xi_{w}=80 \mathrm{~m} / \mathrm{s}^{2}\right.$ instead of $\left.\xi_{w}=500 \mathrm{~m} / \mathrm{s}^{2}\right)$ has been used in order to account for the drag forces. A value of $\gamma^{\prime}=10 \mathrm{kN} / \mathrm{m}^{3}$ has been used for the submerged pathway. This value has been calculated by considering the unit weight of the saturated material $\left(\gamma \sim 20 \mathrm{kN} / \mathrm{m}^{3}\right)$ instead of the unit weight of the soil-water mixture $\left(\gamma \sim 18 \mathrm{kN} / \mathrm{m}^{3}\right)$ that was used in the subaerial slope. Unlike cases 1 and 2 , in case 3 the EFEM approach has been not applied and the same value of the unit weight, friction coefficient $(\mu)$ and turbulence coefficient $(\xi)$ have been set for both the subaerial and submerged paths.

The runout distances that have been computed for cases 1 and 2 are more or less the same and are consistent with the real event (the impact effect does not seem to significantly affect the travel distance); however, there is a significant increase in the runout of case 3 (where the ambient fluid is neglected and the EFEM approach is not used) (Fig. 8).

With regard to the front velocity, profile 1 is completely different from profiles 2 and 3 (Fig. 9), which are very similar
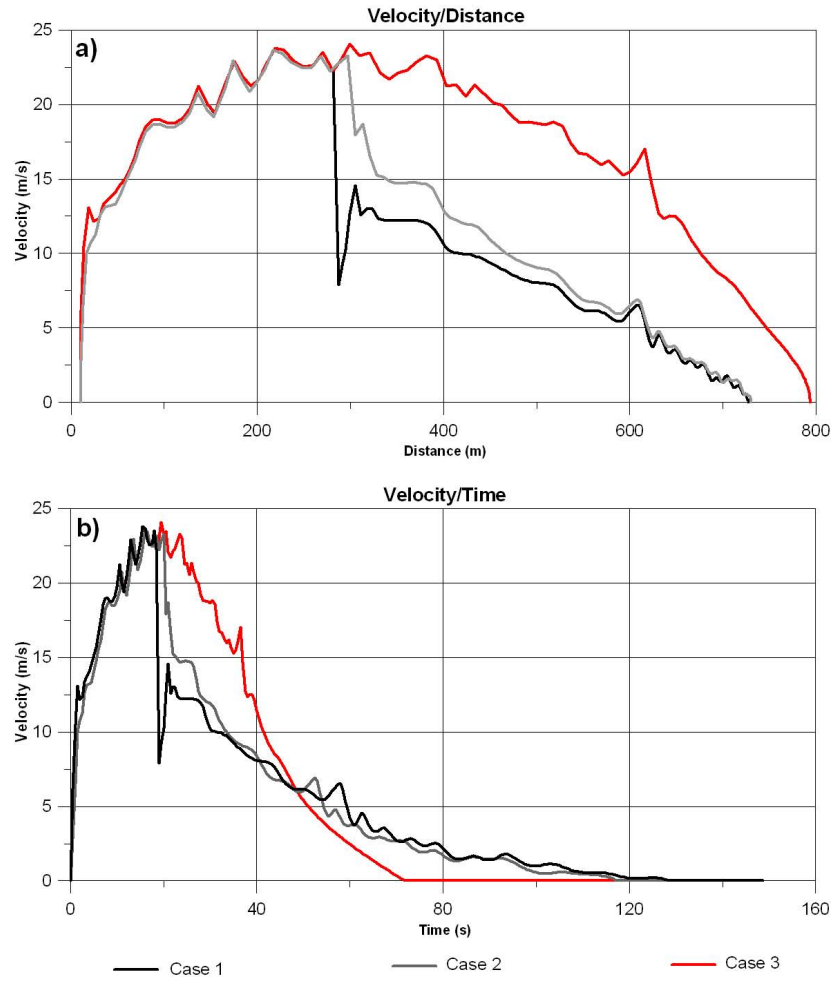

Fig. 9. (a) Front velocity versus distance and (b) Front velocity versus time of the 1997 Lake Albano debris flow obtained in the simulations 1, 2 and 3 of Table 2 .

to one another apart from the sudden reduction of velocity in case 2 that is due to the water impact. The impact effect has only been used to infer qualitative insights since no physical or empirical constraints were available to set a reliable value. A very high frictional layer has been set at the water level in order to observe the reaction of the model and to analyse the obtained results. An interesting phenomenon has been detected, even if it is predictable, in case 1. Apart from the sudden deceleration of the front, significant thickening of the landslide at the water level has also been observed (Fig. 10). 


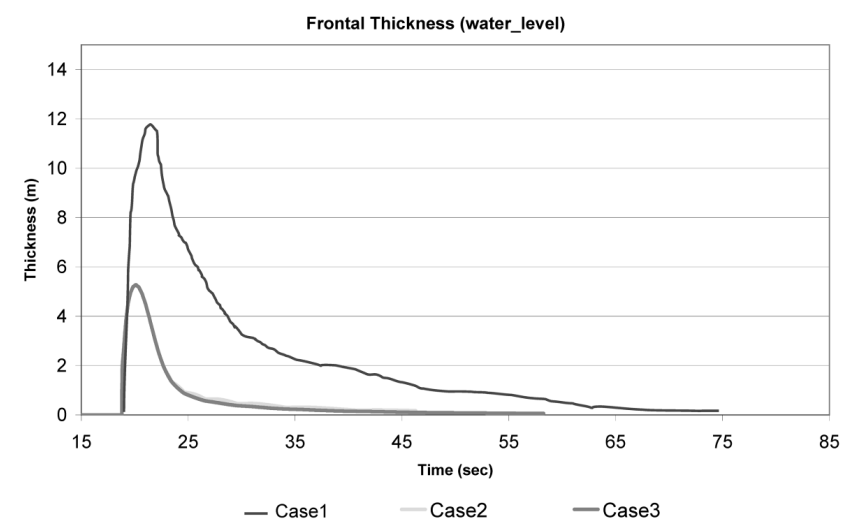

Fig. 10. Front thickness versus time of the 1997 Lake Albano debris flow computed at the lake level in the simulations 1,2 and 3 of Table 2.

The front thickness of the landslide, which was computed $\sim 30 \mathrm{~m}$ below the lake level, shows the highest value in case 2 while cases 1 and 3 reach more or less the same value (Fig. 11).

\section{Concluding remarks}

The proposed approach represents a useful tool for the numerical simulation of coastal and submerged landslides propagation. The approach, even if semi-empirical, is able to account for the main physical mechanisms that control the motion of a landslide in water: buoyancy and drag forces, loss of energy during the impact with water and particular submerged mechanisms like hydroplaning.

The examples herein discussed represent the first step in the calibration of parameters while, at the same time, they suggest the efficacy of the approach when simulating coastal mass movements. The case studies herein discussed do not present conditions that could lead to the triggering of hydroplaning, hence the test of the suggested solution is deferred to future papers.

Such an approach can be applied by using several alreadyexisting models that were originally developed for subaerial landslides, which implement the Voëllmy rheology and that allow the change of properties along the path. Furthermore, due to the high adaptability of some models (like DAN-W), different types of fast landslides can be successfully simulated. Once calibrated upon a large number of real events, this approach could be a useful tool in the field of coastal landslide prediction. Eventually, the results that are obtained from real events, in term of the velocity distribution and volume, could be considered as input data for the simulation of induced tsunamis.

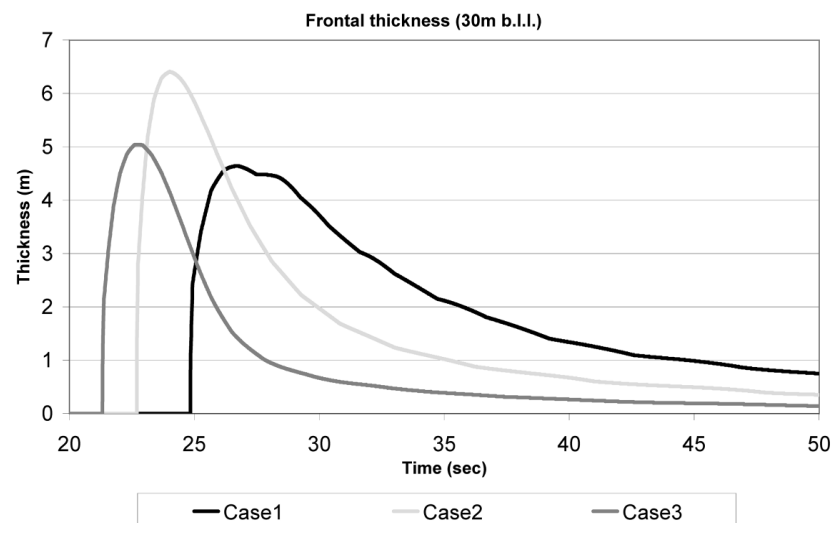

Fig. 11. Front thickness versus time of the 1997 Lake Albano debris flow computed at $30 \mathrm{~m}$ below the lake level in the simulations 1,2 and 3 of Table 2.

Acknowledgements. The authors wish to thank the two reviewers F. V. De Blasio and S. Di Gregorio for useful suggestions and corrections that significantly contributed to the improvement of the paper.

Edited by: T. Glade

Reviewed by: S. Di Gregorio and F. V. De Blasio

\section{References}

Assier-Rzadkiewicz, S., Heinrich, P., Sabatier, P. C., Savoye, B., and Bourillet, J. F.: Numerical Modelling of a Landslidegenerated Tsunami: The 1979 Nice Event, Pure Appl. Geophys., 157, 1707-1727, 2000.

Bagnold, R. A.: Experiments on a gravity-free dispersion of large solid spheres in a Newtonian fluid under shear, Royal Society of London Proceedings. Ser. A, 225, 49-63, 1954.

Bagnold, R. A.: The flow of cohesionless grains in fluids, Royal Society of London Philosophical Transactions. Ser. A, 249, 235297, 1956.

Batchelor, G. K.: An Introduction to Fluid Dynamics, 2nd ed, Cambridge Univ. Press, New York, 1973.

Bertolo, P. and Wieczorek, G. F.: Calibration of numerical models for small debris flows in Yosemite Valley, California, USA, Nat. Hazards Earth Syst. Sci., 5, 993-1001, 2005, http://www.nat-hazards-earth-syst-sci.net/5/993/2005/.

Bozzano, F., Diano, G., Esposito, C., Martino, S., and Mazzanti, P.: The Albano Lake coastal rock slide (Albano, Italy): geological constraints and numerical modelling, in: Landslides and Engineered Slopes, edited by: Chen, Z., Zhang, J., Li, Z., et al., 1, 585-591, ISBN 978-0-415-41196-7, 2008.

Bozzano, F., Mazzanti, P., Anzidei, M., Bianchi Fasani, G.,Esposito, C., Esposito, A., and Floris, M.: Slope dynamics of Lake Albano (Rome, Italy): insights from the high resolution bathymetry, Earth Surf. Proc. Land., 34, 1469-1486, 2009.

Breien, H., Pagliardi, M., De Blasio, F. V., Issler, D., and Elverhøi, A.: Experimental studies of subaqueous vs. subaerial debris flows - velocity characteristics as a function of the ambient fluid, 
in: Submarine Mass Movement and Their Consequence, edited by: Lykousis, V., Sakellariou, D., and Locat, J., 101-110, 2007.

Campbell, C. S., Cleary, P. W., and Hopkins, M.: Large-scale landslide simulations: Global deformations, velocities and basalfriction, J. Geophys. Res., 100, 8267-8283, 1995.

Corominas, J.: The angle of reach as a mobility index for small and large landslides, Can. Geotech. J., 33, 260-271, 1996.

Cruden, D. M. and Varnes, D. J.: Landslide types and processes, in: Landslides Investigation and Mitigation, edited by: Turner, A. K. and Shuster, R. L., Tranportation Research Board. National Research Council, Special Report 247, Washington, DC, 36-75, 1996.

De Blasio, F. V., Engvik, L. E., Harbitz, C. B., and Elverhøi, A.: Hydroplaning and submarine debris flows, J. Geophys. Res., 109, C01002, doi:10.1029/2002JC001714, 2004.

De Blasio, F. V., Engvik, L. E., and Elverhøi, A.: Sliding of outrunner blocks from submarine landslides, Geophys. Res. Lett., 33, L06614, doi:10.1029/2005GL025165, 2006a.

De Blasio, F. V., Elverhøi, A., Engvik, L. E., Issler, D., Gauer, P., and Harbitz, C. B.: Understanding the high mobility of subaqueous debris flows, Norwegian Journal of Geology, 86, 275-284, 2006b.

Denlinger, R. P. and Iverson, R. M.: Flow of variably fluidized granular masses across three-dimensional terrain. 1. Numerical predictions and experimental tests, J. Geophys. Res., 106, 553-566, 2001.

Denlinger, R. P. and Iverson, R. M.: Granular avalanches across irregular three-dimensional terrain: 1 . Theory and computation, $\mathrm{J}$. Geophys. Res., 109, F01014, doi:10.1029/2003JF000085, 2004.

Engvik, L., De Blasio, F. V., and Elverhøi, A.: Small scale simulations of outrunner blocks, Norwegian Journal of Geology, 86, 301-307, 2006.

Fasanella, E. L, Jackson, K. E., Sparks, C. E, and Sareen, A. K.: Water Impact Test and Simulation of a Composite Energy Absorbing Fuselage Section, J. Am. Helicopter Soc., 50(2), 150164, 2005.

Felix, M. and Peakall, J.: Transformation of debris flows into turbidity currents: mechanisms inferred from laboratory experiments, Sedimentology, 53, 107-123, 2006.

Fernández-Nieto, E. D., Bouchut, F., Bresch, D. M., Castro Díaz, J., and Mangeney, A.: A new Savage-Hutter type model for submarine avalanches and generated tsunami, J. Comput. Phys., 227, 7720-7754, 2008.

Harbitz, C. B., Parker, G., Elverhøi, A., Marr, J. G., Mohrig, D., and Harff, P. A.: Hydroplaning of subaqueous debris flows and glide blocks: Analytical solutions and discussion, J. Geophys. Res., 108(B7), 2349, doi:10.1029/2001JB001454, 2003.

Heim, A.: Bergsturz und Menschenleben, Zurich, Fretz and Wasmuth Verlag, 218 pp., 1932.

Hubbard, B., Heald, A., Reynolds, J. M., Quincey, D., Richardson, S. D., Zapata Luyo, M., Santillan Portilla, N., and Hambrey, M. J.: Impact of a rock avalanche on a moraine-dammed proglacial lake: Laguna Safuna Alta, Cordillera Blanca, Peru, Earth Surf. Proc. Land., 30, 1251-1264, 2005.

Hungr, O. and Morgenstern, N. R.: Experiments on the flow behaviour of granular materials at high velocity in an open channel, Geotechnique, 34, 405-413, 1984.

Hungr, O.: A model for the runout analysis of rapid flow slides, debris flows, and avalanches, Can. Geotech. J., 32, 610-623, 1995.
Hungr, O. and Evans, S. G.: Rock avalanche runout prediction using a dynamic model, in: Proceedings of the 7th International Symposium on Landslides, Trondheim, edited by: Senneset. K., A.A. Balkema, Rotterdam., 233-238, 1996.

Hungr, O., Corominas, J., and Eberhardt, E.: Estimating landslide motion mechanism, travel distance and velocity, in: Landslide Risk Management, edited by: Hungr, O., Fell, R., Couture, R., and Eberhardt, E., A.A. Balkema, Leiden, 99-128, 2005a.

Hungr, O. and Evans, S. G.: The occurrence and classification of massive rock slope failure, Felsbau, 22, 16-23, 2004.

Hungr, O., McDougall, S., and Bovis, M.: Entrainment of Material by Debris Flows, in: Debris Flow Hazards and Related Phenomena, edited by: Jakob, M. and Hungr, O., Springer Verlag, Heidelberg, 135-158, 2005b.

Hürlimann, M., Copons, R., and Altimir, J.: Detailed debris flow hazard assessment in Andorra: A multidisciplinary approach, Geomorphology, 78, 359-372, 2006.

Ilstad, T., Marr, J. G., Elverhoi, A., and Harbitz, C. B.: Laboratory studies of subaqueous debris flows by measurements of porefluid pressure and total stress, Mar. Geol., 213, 403-414, 2004.

Imran, J., Harff, P., and Parker, G.: A numerical model of submarine debris flow with graphical user interface, Comput. Geosci., 27, 717-729, 2001.

Iovine, G., Di Gregorio, S., and Lupiano, V.: Debris-flow susceptibility assessment through cellular automata modeling: an example from 15-16 December 1999 disaster at Cervinara and San Martino Valle Caudina (Campania, southern Italy), Nat. Hazards Earth Syst. Sci., 3, 457-468, 2003, http://www.nat-hazards-earth-syst-sci.net/3/457/2003/.

Issler, D.: Experimental information on the dynamics of dry-snow avalanches, in: Dynamic response of granular and porous materials under large and catastrophic deformations, edited by: Hutter, K. and Kirchner, N., 11 of Lecture Notes in Applied and Computional Mechanics. Berlin, Germany, Springer, 109-160, 2003.

Iverson, R. M. and LaHusen, R. G.: Friction in debris flows: Inferences from large-scale flume experiments, in: ASCE Natural Conference on Hydraulic Engineering, edited by: Shen. H. W., $\mathrm{Su}, \mathrm{S}$. T., and Wen, F., American Society of Civil Engineers, San Francisco, 1604-1609, 1993.

Jorstad, F.: Waves generated by landslides in Norwegian fjords and lakes, Norwegian Geotechnical Institute Publication, 69, 13-32, 1968.

Kleefsman, K. M. T., Fekken, G., Veldman, A. E. P, Iwanowski, B., and Buchner, B.: A Volume-of-Fluid based simulation method for wave impact problems, J. Comput. Phys., 206, 363-393, 2005.

Laigle, D. and Coussot, P.: Numerical modelling of mudflows, J. Hydraul. Eng., 123, 617-623, 1997.

Lastras, G., De Blasio, F. V., Canals, M., and Elverhøi, A.: Conceptual and numerical modeling of the Big'95 debris flow, western Mediterranean Sea, J. Sediment. Res., 75, 784-797, 2005.

Locat, J.: Normalized rheological behaviour of fine muds and their flow properties in a pseudoplastic regime, in: Debris Flow Hazard Mitigation: Mechanics, Prediction, and Assessment, Proceedings of First International Conference, Water Resources Division, American Society of Civil Engineers, edited by: Chen, C. L., 260-269, 1997.

Major, J. J. and Pierson, T. C.: Debris flow rheology: experimental analysis of fine-grained slurries, Water Resour. Res., 28, 841- 
857, 1992.

Malet, J. P., Maquaire, O., Locat, J., and Remaitre, A.: Assessing debris flow hazards associated with slow moving landslides: methodology and numerical analyses, Landslides, 1, 8390, 2004.

Marr, J. G., Harff, P. A., Shanmugam, G., and Parker, G.: Experiments on subaqueous sandy gravity flows: the role of clay and water content in flow dynamics and depositional structures, Geol. Soc. Am. Bull., 113(11), 1377-1386, 2001.

Mazzanti, P.: Studio integrato subaereo-subacqueo di frane in ambiente costiero: i casi di Scilla (RC) e del lago di (RM) Albano, Giornale di Geologia Applicata, 8(2), 243-259, 2008a.

Mazzanti, P.: Analysis and modelling of coastal landslides and induced tsunamis, Ph.D. thesis, "Sapienza" University of Rome, Department of Earth Sciences, 212 pp., 2008b.

Mazzanti, P., Bozzano, F., and Esposito, C.: Submerged landslide morphologies in the Albano Lake (Rome, Italy), in: Submarine Mass Movement and Their Consequences, edited by: Lykousis, V., Sakellariou, D., and Locat, J., 243-250, 2007.

Mazzanti, P., Bozzano, F., Avolio, M. V., Lupiano, V., and Di Gregorio, S.: 3-D numerical modelling of submerged and coastal landslides' propagation, in: Submarine Mass Movements and Their Consequences, edited by: Mosher D. C., Shipp C., Moscardelli L., et al., 127-139, 2009.

McDougall, S.: A new continuum dynamic model for the analysis of extremely rapid landslide motion across complex 3-D terrain, Ph.D. thesis, University of British Columbia, 253 pp., 2006.

McDougall, S., Pirulli, M., Hungr, O., and Scavia, C.: Advances in landslide continuum dynamic modelling, in: Landslides and Engineered Slopes, edited by: Chen, Z., Zhang, J., Li, Z., et al., 1, 145-157, ISBN 978-0-415-41196-7, 2008.

McDougall, S. and Hungr, O.: A model for the analysis of rapid landslide motion across three-dimensional terrain, Can. Geotech. J., 41, 1084-1097, 2004.

Mohrig, D., Whipple, K., Ellis, C., and Parker, G.: Hydroplaning of subaqueous debris flows, Geol. Soc. Am. Bull., 110, 387-394, 1998.

O’Brien, J. S., Julien, P. Y., and Fullerton W. T.: Two dimensional water flood and mudflow simulation, J. Hydraul. Eng., 119, 244 259, 1993.

O'Brien, J. S. and Julien, P. Y.: Laboratory analysis of mudflow properties, J. Hydraul. Eng., 110, 877-887, 1988.

Panizzo, A., De Girolamo, P., Di Risio, M., Maistri, A., and Petaccia, A.: Great landslide events in Italian artificial reservoirs, Nat. Hazards Earth Syst. Sci., 5, 733-740, 2005, http://www.nat-hazards-earth-syst-sci.net/5/733/2005/.

Papadopoulos, G. A. and Kortekaas, S.: Characteristics of landslide generated tsunamis from observational data, in: Submarine Mass Movements And Their Consequences, 1st International Symposium, edited by: Locat, J. and Mienert J., Kluver Academic Publishers, 367-374, 2003.

Pearsons, J. D., Whipple, K. X., and Simoni, A.: Experimental study of the grain-flow, fluid-mud transition in debris flows, J. Geol., 109, 427-447, 2001.
Pietrantonio, G., Baiocchi, V., Fabiani, U., Mazzoni, A., and Riguzzi, F.: Morphological updating on the basis of integrated DTMs: study on the Albano and Nemi craters, J. Appl. Geodesy, 2, 239-250, 2008.

Plafker, G. and Eyzaguirre, V. R.: Rock avalanches and wave at Chungar, Perù, in: Rockslides and Avalanches, edited by: Voight B., Engineering sites, Elsevier, Amsterdam, 2, 269-279, 1979.

Revellino, P., Hungr, O., Guadagno, F. M., and Evans, S. G.: Velocity and runout simulation of destructive debris flows and debris avalanches in pyroclastic deposits, Campania region, Italy, Environ. Geol., 45, 295-311, 2004.

Salles, T., Lopez, S., Cacas, M. C., and Mulder, T.: Cellular automata model of density currents, Geomorphology, 88, 1-20, 2007.

Savage, S. B. and Hutter, K.: The motion of a finite mass of granular material down a rough incline, J. Fluid Mech., 199, 177-215, 1989.

Scheidegger, A. E.: On the prediction of the reach and velocity of catastrophic landslides, Rock Mechanics, 5, 231-236, 1973.

Sousa, J. and Voight, B.: Continuum simulation of flow failures, Geotechnique, 41, 515-538, 1991.

Talling, P. J., Peakall, J., Sparks, R. S., Cofaigh, C. O., Dowdeswell, J. A., Felix, M., Wynn, R. B., Baas, J. H., Hogg, A. J., Masson, D. G., Taylor, J., and Weaver, P. P. E.: Experimental constraints on shear mixing rates and processes: implications for the dilution of submarine debris flows, in: Glacier-Influenced Sedimentation on High-Latitude Continental Margins, edited by: Dowdeswell, J. A. and Cofaigh, C. O., Geological Society of London, Special Publication, 203, 89-103, 2002.

Toyos, G., Gunasekera, R., Zanchetta, G., Oppenheimer, C., Sulpizio, R., Favalli, M., and Pareschi, M. T.: GIS-assisted modelling for debris flow hazard assessment based on the events of May 1998 in the area of Sarno, Southern Italy: II. Velocity and dynamic pressure, Earth Surf. Proc. Land., 33, 1693-1708, 2008.

Trigila, R. (Ed.): The Volcano of the Alban Hills, Tipografia SGS Roma, 1995.

Voëllmy, A.: Über die Zerstorungskraft von Lawinen, Schweiz, Bauzeitung, 73, 212-285, 1955.

Von Karman, T.: The impact of sea planes floats during landing, NACA TN, 321, Washington DC, 1929.

Wagner, H.: Uber stoß- und gleitvorgange an der oberflache von flussigkeiten (Phenomena associated with impacts and sliding on liquid surfaces), Z. Angew. Math. Mech., 12, 193-215, 1932.

Wagner, T. P., McKee, C. O., Kuduon, J., and Kombua, R.: Landslide-induced wave in a small volcanic lake: Kasu Tephra Cone, Papua New Guinea, Int. J. Earth Sci., 92, 405-406, 2003.

Wang, C., Esaki, T., Xie, M., and Qiu, C.: Landslide and debrisflow hazard analysis and prediction using GIS in MinamataHougawachi area, Japan, Environ. Geol., 51, 91-102, 2006.

Whipple, K. X.: Open-channel flow of Bingham fluids: applications in debris flow research, J. Geol., 105, 243-257, 1997. 